\title{
Peritonitis fúngica por Rhodotorula mucilaginosa en una paciente en diálisis peritoneal automatizada. Revisión de la literatura
}

\author{
Fernando J. Verdugo, Eduardo Briones, Lorena Porte, José Amaro y Alberto Fica
}

\begin{abstract}
Hospital Militar de Santiago Santiago, Chile.

Servicio de Medicina (FJV), Servicio de Nefrología (EB), Laboratorio Clínico (LP), Servicio de Infectología

$(\mathrm{AF})$.

Universidad de Chile. Programa de Microbiología, Instituto de Ciencias Biomédicas,

Facultad de Medicina (JA)

Conflicto de interés: ninguno Financiamiento: ninguno.

Recibido: 1 de septiembre de 2015 Aceptado: 28 de enero de 2016

Correspondencia a: Fernando J. Verdugo fjverdugo@miuandes.cl
\end{abstract}

\section{Introducción}

L a peritonitis es una complicación mayor de la diálisis peritoneal. La mayoría es de etiología bacteriana. Las peritonitis fúngicas corresponden a $5-10 \%$ de los $\operatorname{casos}^{1-3}$. Se caracterizan por presentar una alta mortalidad cercana a $25 \%{ }^{3}$. Aquellos pacientes que sobreviven, presentan a menudo un daño irreversible o esclerosis de la membrana peritoneal, complicación responsable del retiro de esta terapia en $40 \%$ de los casos ${ }^{3}$. Se describe un caso clínico de una peritonitis fúngica por un agente infrecuente.

\section{Caso clínico}

Mujer de 83 años con antecedentes de diabetes mellitus tipo 2, con buen control metabólico, enfermedad renal crónica etapa 5 con diuresis residual por nefropatía diabética; diabetes mellitus tipo 2 con buen control metabólico; cardiopatía coronaria en tratamiento y portadora de un marcapasos por enfermedad del nodo sinusal. Recibió terapia de reemplazo renal con hemodiálisis por cuatro años, y que posteriormente pasó a diálisis peritoneal (DP) por catéter Tenckhoff por complicaciones secundarias (trombosis de tres fístulas arterio-venosas y disfunción de catéteres de diálisis). Desde el inicio de la DP presentó al menos dos episodios de peritonitis atribuido a una mala técnica de conexión. El último episodio había sido tratado de forma ambulatoria con vancomicina y ceftazidima intraperitoneal. Llevando cuatro años de DP consultó en nuestro centro asistencial por un cuadro clínico de una semana de evolución, con dolor abdominal sordo, difuso y progresivo, de intensidad moderada y asociado a distensión abdominal. No refería sensación febril ni calofríos. Con ausencia de deposiciones durante los últimos tres días, sin otros síntomas. Al examen físico se encontraba hemodinámicamente estable, afebril, con rigidez abdominal y signos de irritación peritoneal. En los exámenes de laboratorio del ingreso destacó una elevación de los parámetros inflamatorios (Figura 1). La tomografía axial computada (TAC) evidenció cambios inflamatorios en el peritoneo adyacente al catéter de DP sin otras alteraciones. Se realizó estudio de líquido peritoneal, el cual era de aspecto grumoso, destacando en el examen citoquímico una leucocitosis de predominio polimorfonuclear (recuento 235 céls $/ \mathrm{mm}^{3}$ con $65 \%$ polimorfonucleares). Se realizaron cultivos del líquido peritoneal en placa de agar chocolate y en botella de hemocultivo automatizado (BacT/Alert, bioMérieux) según el protocolo local. Se inició tratamiento empírico con ciprofloxacina intravenosa en dosis ajustadas a DP automatizada (DPA) y se administró además una dosis única de vancomicina intravenosa y de ceftazidima y vancomicina por vía intraperitoneal.

La paciente evolucionó con una disminución del dolor abdominal, afebril, manteniendo salida de líquido hemático por el catéter, de forma intermitente. Se realizaron con- 
troles de parámetros inflamatorios sistémicos los que no presentaron mejoría (días 1 a 3 en Figura 1), persistiendo un líquido peritoneal grumoso con predominio linfocitario (recuento de 200 céls $/ \mathrm{mm}^{3}$ con $65 \%$ linfocitos). A las $72 \mathrm{~h}$ de evolución, se pesquisó el desarrollo de una levadura de aspecto liso y coloración rosada en una placa de agar chocolate sembrado con la muestra directa. La misma levadura se desarrolló en subcultivos en agar Sabouraud (Figura 2) y ChromID Candida Agar (bioMérieux). Se identificó el mismo agente desde un frasco de hemocultivo inoculado directamente con líquido peritoneal, luego de un traspaso a las $72 \mathrm{~h}$ de inoculación a agar chocolate y agar Chrom ID CPS (bioMérieux). No se identificaron bacterias en ningún cultivo. Se inició fluconazol oral de forma empírica, ajustado a dosis de DP en espera de la tipificación del agente. La terapia con ciprofloxacina se suspendió al quinto día y no se volvieron a administrar nuevas dosis de vancomicina intravenosa ni antimicrobianos intraperitoneales.

La levadura se identificó por tarjeta YST de Vitek 2 compact (bioMérieux) como Rhodotorula mucilaginosa pero con $<99 \%$ de certeza. La tipificación se confirmó por espectrometría de masas (MALDI-TOF) con un equipo Vitek MS (bioMérieux) que permite discriminar tres diferentes especies de este género y que señaló $R$. mucilaginosa con un score de 99,9. Considerando el agente implicado y los signos sugerentes de esclerosis peritoneal en la TAC, se decidió retirar el catéter de DP al quinto día del ingreso. La biopsia mostró un proceso inflamatorio del peritoneo pero con tinción de Grocott negativa para hongos. Tomando en cuenta la resistencia reportada de este agente para fluconazol, se inició posaconazol oral 400 $\mathrm{mg}$, fraccionado cada $12 \mathrm{~h}$, el que se mantuvo por 14 días. Se observó una respuesta clínicamente favorable, con disminución de los parámetros inflamatorios en los controles subsiguientes (Figura 1). Respecto del manejo de la insuficiencia renal crónica, se instaló un catéter venoso central tunelizado para hemodiálisis, sin complicaciones posteriores. Fue dada de alta hospitalaria con tratamiento antifúngico con posaconazol oral. La susceptibilidad a diferentes compuestos fue establecida en forma posterior mediante microdilución en caldo. La paciente evolucionó asintomática y con parámetros inflamatorios normales a un año de seguimiento.

\section{Discusión}

Las peritonitis fúngicas son causadas principalmente por agentes del género Candida ${ }^{3}$. Dentro de las series clínicas de peritonitis fúngica asociada a DP peritoneal, las infecciones por Rhodotorula spp. son infrecuentes, con una prevalencia menor a $2,5 \%$ de $\operatorname{los} \operatorname{casos}^{1,2}$. Estas levaduras son consideradas agentes de baja virulencia en

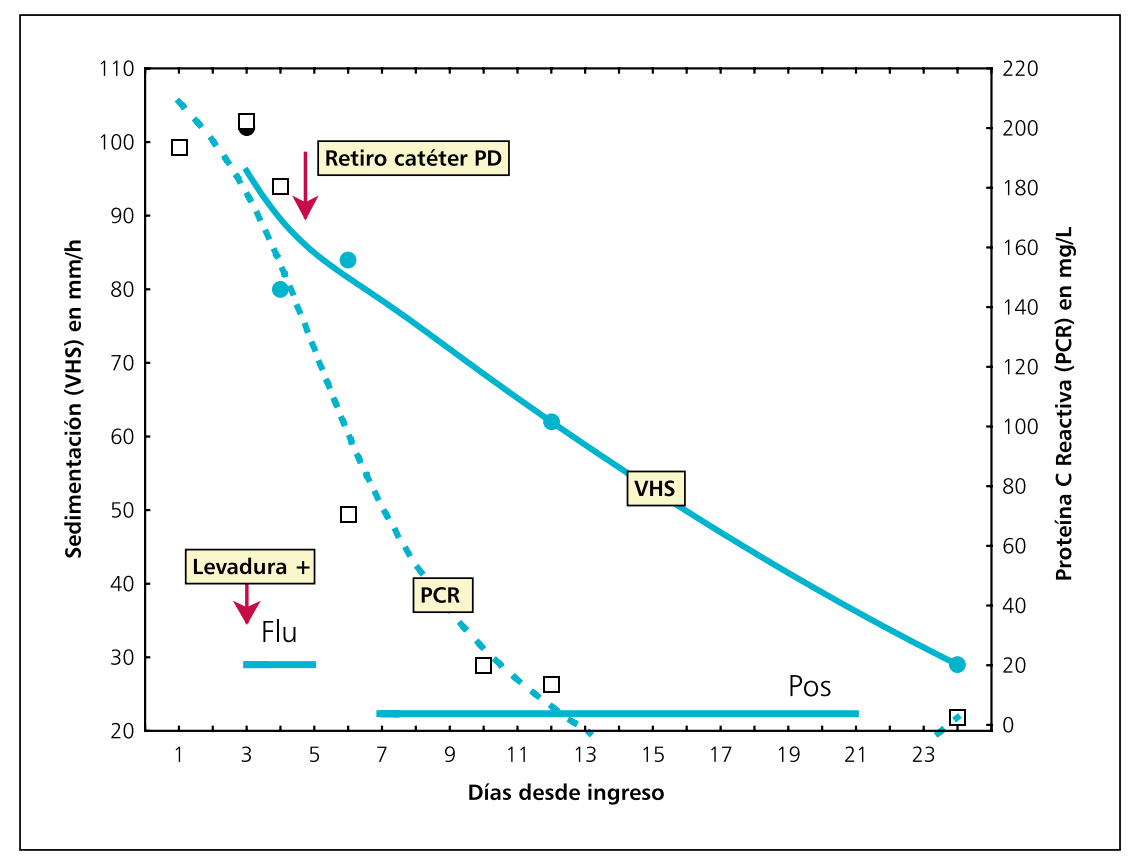

Figura 1. Evolución de parámetros inflamatorios según acciones terapéuticas en caso de peritonitis por Rhodotorula mucilaginosa. Flu (período en terapia con fluconazol) y Pos (período con posaconazol). PD (peritoneodiálisis), PCR (proteína C reactiva), VHS (velocidad de eritrosedimentación).

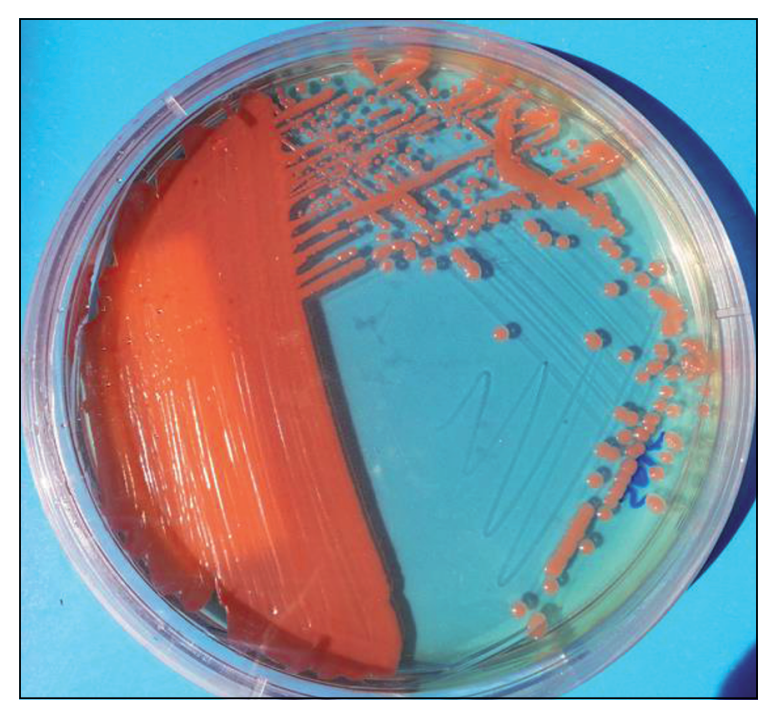

Figura 2. Cultivo de Rhodotorula mucilaginosa en placa de agar Sabouraud Dextrosa incubado a $37{ }^{\circ} \mathrm{C}$ por $24 \mathrm{~h}$. Obsérvese el color rosado de las colonias. comparación a otros hongos y actúan como oportunistas en pacientes con inmunosupresión de cualquier causa, portadores de algún cuerpo extraño o con uso prolongado de antimicrobianos de amplio espectro ${ }^{4,5}$. En la Tabla 1 se resumen los casos publicados de peritonitis fúngica por Rhodotorula $\mathrm{spp}^{6-12}$. En general, la peritonitis por Rhodo- 


\begin{tabular}{|c|c|c|c|c|c|c|}
\hline Autor/referencia & Género & Edad años & Co-morbilidad & ATB & Tratamiento & Desenlace \\
\hline Eisenberg $^{6}$ & M & 16 & No & Sí & $\mathrm{RC}+$ Anfo IP & Curación + HD \\
\hline Eisenberg ${ }^{6}$ & M & 50 & DM2 & Sí & $\mathrm{RC}+$ Anfo IP & Curación + HD \\
\hline Eisenberg $^{6}$ & M & 59 & No & Sí & $\mathrm{RC}+$ Keto VO & Muerte* \\
\hline Flanigan $^{7}$ & M & 31 & No & Sí & $\mathrm{RC}+$ Anfo IP & Curación + HD \\
\hline Wong $^{8}$ & M & 3 & No & Sí & $\mathrm{RC}+$ Anfo IP & Curación + DP \\
\hline Pennington ${ }^{9}$ & $\mathrm{~F}$ & 37 & VIH & Sí & $\mathrm{RC}+$ Anfo $\mathrm{EV}$ & Curación + HD \\
\hline $\mathrm{Asim}^{10}$ & M & 50 & No & No & $\mathrm{RC}+$ Anfo EV & Curación + HD \\
\hline De Zoysa"11 & M & 69 & No & Sí & Keto VO & Curación + DP \\
\hline Soylu ${ }^{12}$ & $\mathrm{~F}$ & 4 & No & No & $\mathrm{RC}+$ Anfo IP & Curación + HD \\
\hline Ünal'13 & $\mathrm{F}$ & 51 & No & Sí & $\mathrm{RC}+$ Anfo EV & Curación + HD \\
\hline Esta comunicación & $\mathrm{F}$ & 83 & DM2 & Sí & $\mathrm{RC}+$ Posa VO & Curación + HD \\
\hline
\end{tabular}

Tabla 2. Concentración inhibitoria mínima de antifúngicos para Rhodotorula mucilaginosa en $\mu \mathrm{g} / \mathrm{mL}$

\begin{tabular}{|c|c|c|c|c|}
\hline & Eisenberg $^{6}$ & Ünal $^{13}$ & Ellis $^{14}$ & Este caso \\
\hline Anfotericina B & 0,01 & 0,13 & 0,50 & 0,12 \\
\hline Fluconazol & ne & 256,0 & $>64,0$ & 64,0 \\
\hline Ketoconazol & 0,10 & 0,06 & ne & ne \\
\hline Itraconazol & ne & 2,0 & 2,0 & 0,12 \\
\hline Voriconazol & ne & 0,5 & 2,0 & 0,50 \\
\hline Posaconazol & ne & ne & ne & 0,25 \\
\hline Caspofungina & ne & 32,0 & $>16,0$ & 2,0 \\
\hline Anidulafungina & ne & ne & ne & 2,0 \\
\hline Micafungina & ne & ne & ne & 2,0 \\
\hline
\end{tabular}

torula se presenta, tanto en población pediátrica como adulta, con uso de antimicrobianos de amplio espectro en $80 \%$ de los casos como potencial factor de riesgo y sólo en $20 \%$ de los casos se describe una co-morbilidad asociada a grados variables de inmunosupresión (VIH, diabetes mellitus tipo 2$)^{6,9}$. Creemos que en nuestra paciente esta levadura tuvo un rol patogénico debido a que se asoció a síntomas, a alteraciones del líquido peritoneal, fue identificada en dos cultivos diferentes sin otros agentes aislados y hubo además, alteraciones en el estudio de imágenes y en el análisis histológico.

La identificación de este agente como causante de peritonitis obliga a un ajuste en el manejo antifúngico. Existen escasas publicaciones de pruebas de susceptibilidad in vitro para $R$. mucilaginosa (Tabla 2). Estos señalan una alta resistencia a fluconazol $\left(\mathrm{CIM}_{90}>64 \mu \mathrm{g} / \mathrm{ml}\right)$ y equinocandinas $\left(\mathrm{CIM}_{90} \geq 16 \mu \mathrm{g} / \mathrm{ml}\right)^{13,14}$. La anfotericina $\mathrm{B}$, el antifúngico más utilizado en infecciones por este agente (Tabla 2), presenta una CIM menor $\left(\mathrm{CIM}_{90} \leq 0,5\right.$ $\mu \mathrm{g} / \mathrm{ml}$ ) pero puede asociarse a un riesgo aumentado de deterioro de la función renal residual. A pesar de presentar concentraciones inhibitorias mínimas bajas, existen pocos reportes del manejo de infección por Rhodotorula con otros triazoles incluyendo ketoconazol ${ }^{5,6,11}$. De acuerdo a nuestro conocimiento, éste sería el primer caso tratado con posaconazol. Esta decisión fue respaldada por el valor elevado de CIM obtenido para fluconazol mediante microdilución en caldo según las pautas del Clinical Laboratory Standard Institute (CLSI) M27 A3 y M27 S4 (Tabla 2).

El retiro del catéter se ha asociado a una menor mortalidad de pacientes con peritonitis fúngica, siendo la conducta actualmente recomendada por la Sociedad Internacional de $\mathrm{DP}^{3}$. Considerando la imposibilidad de realizar una nueva fístula arterio-venosa y con deterioro en accesos vasculares, se intentó mantener el catéter de DP. Sin embargo, al identificarse la presencia de R. mucilaginosa, se decidió retirar el catéter. En $90 \%$ de los casos comunicados ésta ha sido la conducta terapéutica preferida en el manejo de peritonitis por 
Rhodotorula spp., abandonándose definitivamente la DP como terapia de remplazo renal en $88 \%$ de estos pacientes (Tabla 1).

En conclusión, Rhodotorula sp es un agente infrecuente de peritonitis en pacientes con DP que puede fácilmente ser sospechado por la coloración rosada de la colonia que origina su nombre. Su identificación requiere un ajuste del tratamiento antifúngico, debido a su resistencia intrínseca a fluconazol y equinocandinas. El tratamiento requiere la remoción del catéter de DP.

Agradecimientos. A Cecilia Tapia del Programa de Microbiología, Instituto de Ciencias Médicas de la Facultad de Medicina de la Universidad de Chile por la revisión crítica del manuscrito.

\section{Resumen}

La peritonitis fúngica es una complicación mayor de la diálisis peritoneal, con una alta mortalidad asociada y la mayoría de los sobrevivientes presentan una alta tasa de abandono de diálisis peritoneal como terapia de reemplazo renal. Se presenta un caso de peritonitis fúngica por un agente infrecuente. Mujer de 83 años, diabética con múltiples episodios de peritonitis bacteriana asociada a fallas técnicas en la ejecución de diálisis peritoneal automatizada, ingresa por cuadro clínico de dolor abdominal y líquido peritoneal turbio. Se confirmó la presencia de Rhodotorula mucilaginosa en líquido peritoneal mediante MALDI-TOF. Fue tratada con retiro del catéter y posaconazol oral por 14 días, presentando una evolución favorable.

\section{Referencias bibliográficas}

1.- Wang A Y, Yu A W, Li P K, Lam P K, Leung C B, Lai K N, et al. Factors predicting outcome of fungal peritonitis in peritoneal dialysis: analysis of a 9-year experience of fungal peritonitis in a single center. Am $\mathrm{J}$ Kidney Dis 2000; 36: 1183-92.

2.- Bibashi E, Memmos D, Kokolina E, Tsakiris D, Sofianou D, Papadimitriou M. Fungal peritonitis complicating peritoneal dialysis during an 11-year period: report of 46 cases. Clin Infect Dis 2003; 36: 927-31.

3.- Li P K, Szeto C C, Piraino B, Bernardini J, Figueiredo A E, Gupta A, et al. Peritoneal dialysis-related infections recommendations: 2010 Update. Perit Dial Int. 2010; 30: 393-423.

4.- Wirth F, Goldani L Z. Epidemiology of Rhodotorula: an emerging pathogen. Interdiscip Perspect Infect Dis 2012; 2012: 465717.
5.- Tuon F F, Costa S F. Rhodotorula infection. A systematic review of 128 cases from literature. Rev Iberoam Micol 2008; 25: 135-40.

6.- Eisenberg E S, Alpert B E, Weiss R A, Mittman N, Soeiro R. Rhodotorula rubra peritonitis in patients undergoing continuous ambulatory peritoneal dialysis. Am J Med 1983; 75: 349-52.

7.- Flanigan M, Anderson D, Freeman R M. Peritoneal dialysis complicated by fungal peritonitis and peritoneal fibrosis. Am J Med 1984; 76: A113-A125.

8.- $\quad$ Wong V, Ross L, Opas L, Lieberman E. Rhodotorula rubra peritonitis in a child undergoing intermittent cycling peritoneal dialysis. J Infect Dis 1988; 157: 393-4.

9.- Pennington J C 3rd, Hauer K, Miller W. Rhodotorula rubra peritonitis in an HIV+ patient on CAPD. Del Med J 1995; 67: 184.

10.- Asim M, Meigh J A, Farr M J. Fungal peritonitis caused by Candida parapsilosis and subsequently Rhodotorula glutinis in a CAPD patient. Perit Dial Int 1999; 19: 183.

11.- de Zoysa J R, Searle M, Lynn K L, Robson R A. Successful treatment of CAPD peritonitis caused by Rhodotorula mucilaginosa. Perit Dial Int 2001; 21: 627-8.

12.- Soylu A, Demircioglu F, Turkmen M, Yucesoy M, Kavukcu S. Unusual cause of peritonitis during peritoneal dialysis. Rhodotorula rubra and amphotericin B. Pediatr Nephrol 2004; 19: 1426-8.

13.- Ünal A, Koc A N, Sipahioglu M H, Kavuncuoglu F, Tokgoz B, Buldu H M, et al. CAPD-related peritonitis caused by Rhodotorula mucilaginosa. Perit Dial Int 2009; 29: 581-2.

14.- Ellis D, Davis S, Alexiou H, Handke R, Bartley R. Rhodotorula mucilaginosa. En: Bartley R (Ed.). Description of Medical Fungi, $2^{\text {nd }}$ ed. Adelaide, Nexus Print Solutions, 2007: 127 . 